This is the peer reviewed version of the following article: Juthapakdeeprasert, Jindaporn, Gavalda Diaz, Oriol, Lerdprom, Wirat, De Sousa Meneses, Domingos, Jayaseelan, Doni D. and Lee, William E (2020) Reactions and emissivity of cerium oxide with phosphate binder coating on basic refractory brick. International Journal of Applied Ceramic Technology, 17(2), pp. 668-676., which has been published in final form at https:// doi.org/10.1111/ijac.13416. This article may be used for non-commercial purposes in accordance with Wiley Terms and Conditions for Use of Self-Archived Versions 
MISS JINDAPORN JUTHAPAKDEEPRASERT (Orcid ID : 0000-0003-0520-8129)

MR. WIRAT LERDPROM (Orcid ID : 0000-0001-6483-802X)

Article type : Article

Corresponding author mail id: jj1916@ic.ac.uk

\section{Reactions and emissivity of cerium oxide with phosphate binder coating on basic refractory brick}

Jindaporn Juthapakdeeprasert ${ }^{1}$, Oriol Gavalda Diaz ${ }^{1}$, Wirat Lerdprom ${ }^{1}$, Domingos De Sousa Meneses ${ }^{2}$, Doni D. Jayaseelan ${ }^{3}$ and William E Lee ${ }^{1}$

${ }^{1}$ Centre for Advanced Structural Ceramics (CASC), Department of Materials, Imperial College London, South Kensington Campus, London, SW7 2AZ, United Kingdom

${ }^{2}$ CNRS, CEMHTI UPR3079, University Orléans, F-45071 Orléans, France

${ }^{3}$ Department of Aerospace and Aircraft Engineering, Kingston University London, Roehampton Vale Campus, London, SW15 3DW, United Kingdom

\section{Abstract}

High emissivity coatings which aim to help the cement industry reduce heat loss in its production process have been developed with different $\mathrm{CeO}_{2}$ and $\mathrm{AlH}_{6} \mathrm{O}_{12} \mathrm{P}_{3}$ ratios (1:3, 1:5 and 1:12 by volume). The coating slurries were shear thinning and after heat treatment in air at $1300^{\circ} \mathrm{C}, 1^{\circ} \mathrm{C} / \mathrm{min}$, dwell $3 \mathrm{hr}, \mathrm{XRD}$ revealed that $\mathrm{CePO}_{4}$ forms more easily as the $\mathrm{Ce} / \mathrm{P}$ ratio decreases. The composition with a 1:5 ratio of $\mathrm{CeO}_{2}: \mathrm{AlH}_{6} \mathrm{O}_{12} \mathrm{P}_{3}$ was gun sprayed on basic refractory bricks, then heat treated under the same conditions as the slurries. SEM, (S)TEM and EDX were used to study thickness, microstructure and chemical

This article has been accepted for publication and undergone full peer review but has not been through the copyediting, typesetting, pagination and proofreading process, which may lead to differences between this version and the Version of Record. Please cite this article as doi: 10.1111/IJAC.13416

This article is protected by copyright. All rights reserved 
composition of the coatings which revealed that the coating was composed of pores, $\mathrm{CeO}_{2}$ grains, $\mathrm{CePO}_{4}$ grains and M-P-O glass. SEM images show that $\mathrm{CePO}_{4}$ was nucleated from a reaction between $\mathrm{CeO}_{2}$ and $\mathrm{AlH}_{6} \mathrm{O}_{12} \mathrm{P}_{3}$. Consequently, $\mathrm{CePO}_{4}$ grains $\left(\sim 2 \mu \mathrm{m}\right.$ diameter) were smaller than $\mathrm{CeO}_{2}(\sim 10 \mu \mathrm{m}$ diameter $)$. The emissivities of un-coated and coated basic refractory bricks were measured at 1100 and $1300^{\circ} \mathrm{C}$ over the wave number range of $700-12000 \mathrm{~cm}^{-1}$. At both temperatures, the emissivity of the coated bricks was higher than the uncoated bricks and the emissivity was measured to be higher at a higher temperature for both samples. The coated bricks gave the highest emissivity of $0.81 \mathrm{from} 1050-11000 \mathrm{~cm}^{-1}$ which is about twice the un-coated bricks for the same conditions. This demonstrates that the developed high emissivity coating has potential to be used with basic refractory brick.

\section{Introduction}

Energy intensive (high temperature) industries face a challenge to enhance energy efficiency and retain as much heat in process as possible. The cement industry is a major energy consumer and cement production uses $3.4 \mathrm{GJ} /$ ton clinker, and the global production is now over 2 billion metric tons annually ${ }^{1,2}$. Most energy consumption in the cement industry is from heating raw materials to $1450^{\circ} \mathrm{C}$ in a kiln to achieve required phases; $3 \mathrm{CaO} \cdot \mathrm{SiO}_{2}, 2 \mathrm{CaO} \cdot \mathrm{SiO}{ }_{2}, 3 \mathrm{CaO} \cdot \mathrm{Al}_{2} \mathrm{O}_{3}$ and $4 \mathrm{CaO} \cdot \mathrm{Al}_{2} \mathrm{O}_{3} \cdot \mathrm{Fe}_{2} \mathrm{O}_{3}$. To make the production more efficient, kilns are continually heated to avoid shutdown cycles where most heat energy is consumed. However, maintaining the kiln at $1450^{\circ} \mathrm{C}$ requires high amounts of energy due to the temperature difference between inside and outside (environment) of the kiln causing heat loss. This problem can be lowered by reducing heat transfer between the kiln contents and liner materials.

Attempts have been made to reduce the thermal conductivity of refractory bricks used in the cement kiln by using lightweight, porous and foamed materials ${ }^{3-5}$. However, the addition of these materials lowers the strength of the refractory bricks and could lead to operational failure. Also, changing the refractory lining in cement kilns is not an ideal solution because it is a high cost process and requires significant down time. Thermal convection is dependent on the velocity of the fluid (gas or liquid) that carries away the heat which is difficult to setup and control in a large-scale manufacturing process like cement production. Thermal radiation is the most interesting among the heat transfer mechanisms because it is highly dependent on temperature difference (to the $4^{\text {th }}$ power as in Equation 1 ) making it a more dominant heat transfer mechanism than thermal conduction and convection especially at high temperature ${ }^{6}$.

$$
Q_{\text {rad }}=\operatorname{A\varepsilon } \sigma\left(T_{w}^{4}-T_{o}^{4}\right)
$$

where $Q_{\text {rad }}$ is heat in Watts $(W)$

This article is protected by copyright. All rights reserved 
$A$ is area of heat transfer surface $\left(\mathrm{m}^{2}\right)$

$\varepsilon$ is surface emissivity

$\sigma$ is the Stefan-Boltzmann constant $\left(5.67 \times 10^{-8} \mathrm{~W} / \mathrm{m}^{2} \mathrm{~K}^{4}\right)$

$\mathrm{T}_{\mathrm{w}}$ is surface temperature $(\mathrm{K})$

$\mathrm{T}_{\mathrm{o}}$ is ambient temperature $(\mathrm{K})$

Equation 1 reveals that thermal radiative heat transfer is dependent only on the area of the heat transfer surface and not the whole volume, therefore, only the surface of the refractory bricks needs to be treated. Developing a highly radiative coating means the original refractory bricks can still be used. However, coatings are not appropriate for every zone of the cement rotary kiln. The coating zone, where there is the highest temperature $\left(\sim 1450^{\circ} \mathrm{C}\right)$ has a partial melt clicker coating on the refractory lining making it an inappropriate zone. The upper transition zone is the zone that has the second-highest temperature $\left(\sim 1300^{\circ} \mathrm{C}\right)$ but not high enough to form clinker coating making it a suitable zone for a radiative coating. Therefore, application of highly radiative coatings is aviable approach for cement industry energy saving.

The high radiative coating functions by absorbing thermal energy then radiating it back into the process and reduce the heat transferring to the external environment. Emissivity plays an important role when aiming to develop highly thermal radiative coatings because it is the only factor in Equation 1 that is a material property. Therefore, materials with high emissivity such as rare earth containing compounds, are frequently used as radiative coatings or as thermal barriers for high temperature applications in spacecraft and gas turbines ${ }^{7-9}$. Rare earth materials can be used as pure materials or added as dopants to others materials such as zirconia, zirconium silicate, alumina, aluminium silicates, silica and $\mathrm{ZrB}_{2} / \mathrm{SiC}$ to improve their emissivity properties $7,8,10,11$. Cerium oxide $\left(\mathrm{CeO}_{2}\right)$ is the most common rare earth material used due to its high melting point $\left(2477^{\circ} \mathrm{C}\right)$, high emissivity $\left(0.9\right.$ from $\left.1000-2000^{\circ} \mathrm{C}\right)$, good base and acid chemical resistance properties and relatively low cost. However, $\mathrm{CeO}_{2}$ has been widely used for high temperature coatings on nickel-based alloy substrates but not basic refractory bricks ${ }^{7-9}$. This study attempted to understand if it is possible to use $\mathrm{CeO}_{2}$ as a coating raw material on a basic refractory that can emit heat. To do so, a binder must also be used to enable application and attachment of $\mathrm{CeO}_{2}$ onto the substrate. Phosphate binder is a known binder that can resist high temperature and therefore was chosen for this study ${ }^{4,12,13}$.

This article is protected by copyright. All rights reserved 


\section{Experimental procedure}

The substrate used in this work is a basic refractory; $\mathrm{BR}\left(80 \mathrm{wt} \% \mathrm{MgO}\right.$ and $20 \mathrm{wt} \% \mathrm{MgAl}_{2} \mathrm{O}_{4}$ ), supplied by The Siam Refractory Industry Co., Ltd, Saraburi, Thailand. The coating slurry was prepared by mixing $\mathrm{CeO}_{2}$ with average particle size of $10 \mu \mathrm{m}$ (cerium (IV) oxide, 99.5\%, Alfa Aesar, Lancashire, England) with $\mathrm{AlH}_{6} \mathrm{O}_{12} \mathrm{P}_{3}$ binder (50 wt\% aqueous solution, Alfa Aesar, Lancashire, England) in the ratios 1:3, 1:5 and 1:12 by volume using a magnetic stirrer for $2 \mathrm{~h}$. The coatings were characterised in both slurry (rheology) and solid (phase analysis, microstructure and emissivity) form.

Rheology of three different compositions was measured using a hybrid rheometer, (Discovery HR-1, TA Instruments, Delaware, USA). Rheology was determined by measuring the viscosity of the slurry with shear rates ranging from $1-100 \mathrm{~s}^{-1}$ at $25^{\circ} \mathrm{C}$ within 60 seconds. Three measurements were made for each composition and the curves were used to understand the viscosity of the three coatings.

Phase analysis was carried out for the three coating compositions. After mixing, the coating slurries were heat treated with heating rate of $10^{\circ} \mathrm{C} / \mathrm{min}$ to $1300^{\circ} \mathrm{C}$ with $3 \mathrm{~h}$ dwell. The coatings were then ground in a mortar with a pestle to powder $<150 \mu \mathrm{m}$. The powder was then analysed by X-ray diffraction (XRD, D2 phaser, Bruker, Germany) using Cu-Ka radiation of wavelength, $1.54 \AA ̊$ over 25-60 $2 \theta$ with count time of 1 second and step size of $0.034^{\circ}$. The peaks were identified with powder diffraction file standards from the International Centre for Diffraction (ICDD); PDF-4+ card 00-034-0394 for $\mathrm{CeO}_{2}$ and 00-032-0199 for $\mathrm{CePO}_{4}$.

The coating with 1:5 ratio of $\mathrm{CeO}_{2}: \mathrm{AlH}_{6} \mathrm{O}_{12} \mathrm{P}_{3}$ was selected for the microstructure analysis and emissivity measurements. The ratio of 1:5 was chosen because it was fluid enough to be sprayable (1:12 was not sufficiently viscous) and contained enough $\mathrm{CeO}_{2}$ content to make the principle cost of the coating reasonable. 1:3 has sprayable viscosity but has higher $\mathrm{CeO}_{2}$ content than 1:5 and therefore the principle cost is higher. The coating was prepared by the same procedure as for the rheology study. After mixing, the slurry was gun sprayed (coated) onto the BR. The coated BR (CBR) samples were dried overnight at room temperature, and then heat treated with a heating rate of $1{ }^{\circ} \mathrm{C} / \mathrm{min}$ for $3 \mathrm{~h}$ at $1300^{\circ} \mathrm{C}$. The thickness and microstructure of the coating cross section was analysed using scanning electron microscopy (SEM, Zeiss Leo Gemini 1525, Oberkochen, Germany) at an accelerating voltage of 5-20 kV using secondary electron imaging. Semi-quantitative area chemical analysis was performed using energy-dispersive spectroscopy (EDX, X-MaX20, Oxford Instruments, Abingdon, UK). The average atomic percentages of each phase were measured in three different areas.

This article is protected by copyright. All rights reserved 
CBR 1:5 microstructure was further studied via TEM/STEM JEM-2100F (JEOL, Japanese Electron Optics Limited, Japan) equipped with an EDX X-Max detector (Oxford Instruments, Abingdon, UK). The sample was imaged at an accelerating voltage of $200 \mathrm{kV}$. Electron transparent samples were prepared following a standard FIB (Focussed Ion Beam) lift-out technique with a DualBeam Helios NanoLab SEM (FEI, Field Electron and Ion Company, USA), from cross sections of the coating which was applied on the substrate and heat treated as for the samples prepared for the SEM.

The heat transfer performance of coatings was defined by emissivity. Emissivity measurements were carried out at CNRS-CEMHTI ${ }^{14}$. The emissivity apparatus consisted of two Bruker spectrometers; Vertex $80 \mathrm{~V}$ and Vertex 70 (Germany). Vertex $80 \mathrm{~V}$ was used for measuring emissivity in the $700-4000 \mathrm{~cm}^{-1}$ range (mid-IR) with DLaTGS/KBr detector. Vertex 70 was used to measured two ranges; $4000-9000 \mathrm{~cm}^{-1}$ (nearIR) with InGaAs detector and 9000-12000 cm-1 (near-IR) with Si-diode detector. After measuring the emissivity of the three wavenumber ranges, data were merged creating emissivity data ranging from 700$12000 \mathrm{~cm}^{-1}$ (mid-IR to near-IR). For each individual measurement over each wavenumber range, three sub-measurements were carried out; flux measurement of the sample, blackbody furnace and ambient contribution. Flux of the sample and blackbody furnace were needed to calculate the emissivity referring to the definition which is flux emitted from the sample surface over flux emitted by a blackbody at the same temperature. Ambient (background) contribution was determined so the effect of the instrument surrounding could be removed giving a more accurate emissivity measurement.

$\mathrm{BR}$ and $\mathrm{CBR}$, were heated with a $\mathrm{CO}_{2}$ laser and their emissivity was measured at 1100 and $1300^{\circ} \mathrm{C}$. The $\mathrm{CO}_{2}$ laser power determines the sample temperature. Five powers were used in this experiment, to achieve temperatures shown in Table 1. From Table 1, power of 54 and 71 watts gave the closest temperature to 1100 and $1300^{\circ} \mathrm{C}$, respectively for $\mathrm{BR}$ and power of 71 and 100 watts gave the closest temperature to 1100 and $1300^{\circ} \mathrm{C}$, respectively for $\mathrm{CBR}$. The $\mathrm{BR}$ and $\mathrm{CBR}$ used different power to reach the same temperature because material with higher heat absorption required higher power to reach desired temperature. With an average of $20^{\circ} \mathrm{C}$ fluctuation of the instrument shown in previous study, these power levels were chosen for emissivity analysis ${ }^{14}$.

\section{Results and Discussion}

Coating viscosities (Pa.s) at different shear rates (1/s) on a log scale are shown in Figure 1 . The slurry with the ratio of $1: 3$ has the highest viscosity followed by $1: 5$ and 1:12. This is attributed to the solid $\left(\mathrm{CeO}_{2}\right.$ powder) content. All three coating compositions reveal a shear thinning effect; viscosity decreases as the 
shear rate increases. Shear thinning is a pre-requisite for the surface coatings. This is because the coating is applied onto the substrate via gun air spraying where low viscosity is required when pressure (high shear rate) is applied to push the coating through the nozzle. When the slurry is coated on the substrate (low shear rate) it is required to have a high viscosity so that it does not slip off. This is shown schematically in Figure 2.

Phases of the three coatings containing different volume ratios of $\mathrm{CeO}_{2}: \mathrm{AlH}_{6} \mathrm{O}_{12} \mathrm{P}_{3}$ (1:3, 1:5 and 1:12) were analysed by XRD (Figure 3) revealing different phases present in the coatings. Figure 3a reveals that all three coatings contain $\mathrm{CeO}_{2}$ and $\mathrm{CePO}_{4} \cdot \mathrm{CeO}_{2}$ is from the raw material and $\mathrm{CePO}_{4}$ is from the reaction between $\mathrm{CeO}_{2}$ and $\mathrm{AlH}_{6} \mathrm{O}_{12} \mathrm{P}_{3}{ }^{15}$. Mixing different $\mathrm{CeO}_{2}$ : $\mathrm{AlH}_{6} \mathrm{O}_{12} \mathrm{P}_{3}$ ratios consequently gives rise to different amounts of $\mathrm{CePO}_{4}$ phase and unreacted $\mathrm{CeO}_{2}$ as indicated by different peak intensities/area. As expected, the 1:3 ratio $\mathrm{CeO}_{2}: \mathrm{AlH}_{6} \mathrm{O}_{12} \mathrm{P}_{3}$ has the highest $\mathrm{CeO}_{2}$ content, therefore, after heat treating, it has the highest $\mathrm{CeO}_{2}$ and the lowest $\mathrm{CePO}_{4}$ peak intensities. $\mathrm{CeO}_{2}$ peak intensity decreases and $\mathrm{CePO}_{4}$ peak intensity increases as the $\mathrm{CeO}_{2}: \mathrm{AlH}_{6} \mathrm{O}_{12} \mathrm{P}_{3}$ ratio decreases. This can be seen clearly in Figure $3 \mathrm{~b}$ which is a magnified image of Figure $3 a$ (2theta ranging from $25-35^{\circ}$ ) where the highest peaks of both $\mathrm{CeO}_{2}$ and $\mathrm{CePO}_{4}$ are presented.

The formation of $\mathrm{CePO}_{4}$ from $\mathrm{CeO}_{2}$ and $\mathrm{AlH}_{6} \mathrm{O}_{12} \mathrm{P}_{3}$ is consistent with previous studies. Tsuhaka et al. [13] prepared rare earth phosphate in various ways. One was mixing cerium oxide $\left(\mathrm{CeO}_{2}\right)$ with phosphoric acid $\left(\mathrm{H}_{3} \mathrm{PO}_{4}\right)$ in $\mathrm{Ce} / \mathrm{P}$ ratios $(\mathrm{R})$ from 1-50 and heat treating for $20 \mathrm{~h}$ at $800^{\circ} \mathrm{C}$. They reported that most $\mathrm{CePO}_{4}$ forms when $\mathrm{R}=1-2$. At higher $\mathrm{Ce} / \mathrm{P}$ atomic ratios other phases also form such as $\mathrm{CeP}_{2} \mathrm{O}_{7} \mathrm{Ce}\left(\mathrm{PO}_{3}\right)_{3}$ and $\mathrm{Ce}\left(\mathrm{PO}_{3}\right)_{4}$. This means that the lower the Ce/P ratio the more $\mathrm{CePO}_{4}$ can be formed ${ }^{16}$. In this experiment, the ratios of $\mathrm{CeO}_{2}$ to $\mathrm{AlH}_{6} \mathrm{O}_{12} \mathrm{P}_{3}$ were 1:3, 1:5 and 1:12 vol ratios which are 2.5, 1.2 and $0.5 \mathrm{Ce} / \mathrm{P}$ atomic ratios respectively. The $1: 5$ vol ratios $(1.2 \mathrm{Ce} / \mathrm{P}$ atomic ratios) fall into the $\mathrm{R}=1-2$ range and therefore show higher XRD intensity of $\mathrm{CePO}_{4}$ than in the $1: 3$ ratios (2.5 atomic ratios). This trend is similar to that reported by Tsuhaka et al [13] i.e. the lower the amount of $\mathrm{CeO}_{2}$ in the system, the easier $\mathrm{CePO}_{4}$ can be formed.

The microstructure of the 1:5- $-\mathrm{CeO}_{2}: \mathrm{AlH}_{6} \mathrm{O}_{12} \mathrm{P}_{3}$ cross section was analysed using SEM. Examination of the coating (Figure 4a) clearly distinguished the coating and substrate. Coating thickness was $290 \pm 15 \mu \mathrm{m}$ measured from Figure $4 a$. The coating contained 4 features; pores, large grains $(\sim 10 \mu \mathrm{m})$, small grains $(\sim 2 \mu \mathrm{m})$ and a phase with a smoothed morphology indicative of melting (matrix). The 4 features are shown in Figure $4 \mathrm{~b}$. Pores are generated from dehydrogenation of $\mathrm{AlH}_{6} \mathrm{O}_{12} \mathrm{P}_{3}$ as temperature increases ${ }^{13,17}$. The large and small grains were identified by EDX analysis as $\mathrm{CeO}_{2}$ and $\mathrm{CePO}_{4}$ respectively (Figure 4c). $\mathrm{CePO}_{4}$ 
formed by a nucleation mechanism and therefore the grains are much smaller than $\mathrm{CeO}_{2}$. The matrix is mostly composed of magnesium $(\mathrm{Mg})$, phosphorus $(\mathrm{P})$ and oxygen $(\mathrm{O})$, also revealed by EDX. Magnesium is from the substrate, phosphorus from the binder and oxygen from both. The atomic ratio of the Mg-P-O is close to 1:1:4 and therefore, it is likely that this matrix is magnesium phosphate $\left(\mathrm{MgPO}_{4}\right)$. EDX mapping in Figure 5 confirms that there was no obvious reaction between the substrate ( $\mathrm{MgO}$ and $\mathrm{MgO} \cdot \mathrm{Al}_{2} \mathrm{O}_{3}$ spinel) and the coating $\left(\mathrm{CeO}_{2}, \mathrm{CePO}_{4}\right.$ and matrix). There was only slight $\mathrm{MgO}$ migration from the substrate into the coating and of $\mathrm{P}$ from the coating into the substrate.

The microstructures revealed by this experiment combined with previous studies ${ }^{12}$ on interactions between $\mathrm{CeO}_{2}$ and $\mathrm{AlH}_{6} \mathrm{O}_{12} \mathrm{P}_{3}$ make it possible to produce a schematic (Figure 6) of how the coating changes as temperature increases. At room temperature, the coating contained two materials which are $\mathrm{CeO}_{2}$ and $\mathrm{AlH}_{6} \mathrm{O}_{12} \mathrm{P}_{3}$ in the ratio of 1:5 vol. When the coating was left to dry, $\mathrm{CeO}_{2}$ particles sediment. When heat is given to the system and increases the temperature, dehydrogenation of $\mathrm{AlH}_{6} \mathrm{O}_{12} \mathrm{P}_{3}$ occurs generating pores. Pores rising to the surface of the coating bringing along some of the $\mathrm{CeO}_{2}$ and $\mathrm{CePO}_{4}$ particles with them. As temperature continues to increase, $\mathrm{CePO}_{4}$ forms ${ }^{15,16}$. At the same time, remaining $\mathrm{CeO}_{2}$ particles sinter. To achieve a more homogeneous coating, a dispersion can be added to avoid sedimentation of $\mathrm{CeO}_{2}$. However, due to the large particle size $(\sim 10 \mu \mathrm{m})$ of the $\mathrm{CeO}_{2}$, which was used as commercially received, and high density (heavy), the $\mathrm{CeO}_{2}$ powder might need to be subject to further grinding.

Transformation of $\mathrm{CeO}_{2}$ to $\mathrm{CePO}_{4}$ influences the coatings light emission behaviour in the visible range (12500-25000 $\left.\mathrm{cm}^{-1}\right)$ because $\mathrm{CeO}_{2}$ contains $\mathrm{Ce}^{4+}$ while $\mathrm{CePO}_{4}$ contains $\mathrm{Ce}^{3+}$. The significant difference between the 2 valence states of $\mathrm{Ce}$ is that the $\mathrm{Ce} 4 \mathrm{f}$ orbital in the $\mathrm{Ce}^{4+}$ electronic structure participates in the chemical bonding of $\mathrm{CeO}_{2}$ and partially loses its $\mathrm{f}$-character so it does not have a valence band close to the Fermi edge ( $<2.5 \mathrm{eV}$ difference). Having a valence band close to the Fermi edge can benefit emissivity in the visible range because lower energy; possibly as low as $2.5 \mathrm{eV}$, is needed for the electrons to be absorbed and become excited before the energy is re-emitted ${ }^{18,19}$. However, this study is more concerned with heat emission which is in the infrared range and $\mathrm{CeO}_{2}$ and $\mathrm{CePO}_{4}$ would be expected to give similar emissivity in this range because infrared electromagnetic wave energy is only high enough to vibrate/rotate the bonds and not to excite electrons from valence band to a excited state.

Further study on the microstructure was done with (S)TEM and EDX. The area selected for the characterization contained the small particles and matrix as shown in Figure 7a. EDX was used to conduct element mapping to understand the chemical composition, Figure $7 \mathrm{~b}$, revealing that the particles contained Ce-P-O and the matrix contained M-P-O. Matching the EDX mapping with the XRD analysis 
indicates that the particles are $\mathrm{CePO}_{4}$. As confirmed by electron diffraction (Figure 7c). The d-spacings and plane angles were measured and compared with the $\mathrm{CePO}_{4}$ electron diffraction pattern reference revealing a match with $\mathrm{CePO}_{4}$ monoclinic single crystal structure down the [001] zone axis. As for the matrix, Figure $7 d$, the likely melted phase did not show any diffraction spots confirming it has a glassy structure. Therefore, the likely melted phase is magnesium phosphate glass.

Emissivity results of $B R$ and CBR samples measured at 1100 and $1300 \circ C$ are shown in Figure 8. Figure 8a reveals emissivity of $\mathrm{BR}$ at $1100,1300^{\circ} \mathrm{C}$ and $\mathrm{CBR}$ at $1100^{\circ} \mathrm{C}$ decreases in the wavenumber range of 1000$3000 \mathrm{~cm}^{-1}$. This is a trend commonly observed for dielectric materials. However, as the wavenumber continues to increase, the emissivity starts to increase. As Kirchhoff's law implies that the microscopic mechanisms producing thermal emission are also responsible for absorption at the same wavelengths, explaining emission can be made by a discussion of the origin of absorption. In general, absorption is separated into 3 mechanisms; interband absorption, free-carrier absorption and lattice absorption. Interband absorption is when electrons are excited over an interband (move from a valence band to another band). Interband absorption mostly occurs in the short wavelength range (visible-ultraviolet) due to it requires the energy to excite the electrons over a wide bandgap. Free-carrier absorption is electrons/holes excited by absorbing a photon and move over an intraband (mover from a filled state to an empty state but in the same band). It occurs in metals and semiconductors. Lattice absorption comes from the atomic vibrations (phonons in crystals, typically below $1500 \mathrm{~cm}^{-1}$ ). In ceria, the strong decrease of emissivity in the wavenumber range of $1000-3000 \mathrm{~cm}^{-1}$ is due to the nearly exponential decrease of the absorption coefficient induced by multi-phonon processes (20). The progressive increase of emissivity at higher wavenumbers is typical of the response of charge carriers that are not completely free (electronic or hole defects). Their hoping motions are coupled to lattice vibrations (like polaronic absorption). In the case of small polarons, the spectral dependence of the contribution of the hoping motions to the absorption is similar to that observed in Figure 8 and is given by a Debye model. So, for this kind of dielectric materials, the total emissivity is from the charge-carrier absorption and lattice absorption. The emissivity becomes steady from $7000-11000 \mathrm{~cm}^{-1}$. CBR shows a different emissivity spectrum. Its emissivity becomes steady at 0.81 from $3000-12000 \mathrm{~cm}^{-1}$. Figure $8 \mathrm{~b}$ is a magnified image from a section in Figure 8a revealing that the Christiansen points of the BR and CBR are in the $800-1000 \mathrm{~cm}^{-1}$ range. Christiansen points appear at the wavenumber corresponding to the highest emissivity level. They occur when a material's specific frequency for which the refractive index is nearly equal to 1 and its absorption coefficient has a moderate value. These two characteristics explain the very high absorption efficiency of the material and that the compound emits like a blackbody ${ }^{21}$. Other than the Christiansen point, Figure $8 b$

This article is protected by copyright. All rights reserved 
also revealed two other events. First, a dip of emissivity in the wavenumber range of $950-1050 \mathrm{~cm}^{-1} \mathrm{due}$ to stretching motions of $\mathrm{PO}_{4}$ tetrahedra. Second, a sharp dip at $1870-1900 \mathrm{~cm}^{-1}$ which was a measurement artefact from the $\mathrm{CO}_{2}$ laser. Comparing the emissivity between $\mathrm{BR}$ and $\mathrm{CBR}$ shows that the coating improves the emissivity of BR especially at $1300^{\circ} \mathrm{C}$ by $120 \%$ (Figure 8 ). As the temperature increase, there is an activation of charge hoping in the $\mathrm{CeO}_{2} / \mathrm{CePO}_{4}$ applied coating which leads to higher absorption/emission. This suggests that $\mathrm{CeO}_{2}$ and $\mathrm{AlH}_{6} \mathrm{O}_{12} \mathrm{P}_{3}$ can provide a high emissivity coating on basic based refractories for high temperature application.

\section{Conclusions}

Mixtures of $\mathrm{CeO}_{2}$ and $\mathrm{AlH}_{6} \mathrm{O}_{12} \mathrm{P}_{3}$ heated with a rate of $1^{\circ} \mathrm{C} / \mathrm{min}$ for $3 \mathrm{~h}$ at $1300^{\circ} \mathrm{C}$ were examined as a potential coating for basic refractory bricks for application in cement kiln linings. Rheology studies show a shear thinning effect which is beneficial for the spraying process and the coating adhesion after spraying. XRD of the coating after heat treatment shows that $\mathrm{CePO}_{4}$ formed more easily as $\mathrm{CeO}_{2}: \mathrm{AlH}_{6} \mathrm{O}_{12} \mathrm{P}_{3}$ ratio decreases. SEM revealed that the coating heat treated to $1300^{\circ} \mathrm{C}$ contained pores, $\mathrm{CePO}_{4}$ nucleated from $\mathrm{CeO}_{2}$ reacting with $\mathrm{AlH}_{6} \mathrm{O}_{12} \mathrm{P}_{3}$, and melt like phase. TEM analysis confirmed that the nucleated particles are $\mathrm{CePO}_{4}$ and the melt like phase is Mg-P-O glass. Coated brick emissivity after heating to $1300^{\circ} \mathrm{C}$ shows a significant improvement of $120 \%$ compared to un-coated brick. To reach the ultimate goal of the coating to act efficiently in the cement rotary kiln, abrasion, thermal shock and corrosion resistance should be studied further.

\section{Acknowledgement}

JJ was supported by SCG Cement-Building Material Co., Ltd, Bangkok, Thailand.

\section{References}

1. Madlool N, Saidur R, Rahim N, Kamalisarvestani M. An overview of energy savings measures for cement industries. Renewable and Sustainable Energy Reviews. 2013;19:18-29.

2. Engin T, Ari V. Energy auditing and recovery for dry type cement rotary kiln systems-A case study. Energy conversion and management. 2005;46(4):551-62.

3. Cheng J-JA, Martinez WA, Hale AP. Lightweight tundish refractory composition. United States Patent Office, 3150989; 1991.

4. Abyzov VA. Lightweight refractory concrete based on aluminum-magnesium-phosphate binder. Procedia Engineering. 2016;150:1440-5.

This article is protected by copyright. All rights reserved 
5. Macey CL, Knauss RJ. Low thermal conductivity magnesite-spinel brick and method. United States Patent, 4833109; 1989.

6. Modest MF. Radiative heat transfer: Academic press; 2013.

7. Huang J, Fan C, Song G, Li Y, He X, Zhang X, et al. Enhanced infrared emissivity of $\mathrm{CeO}_{2}$ coatings by La doping. Applied Surface Science. 2013;280:605-9.

8. Huang J, Li Y, Song G, Zhang X, Sun Y, He X, et al. Highly enhanced infrared spectral emissivity of porous $\mathrm{CeO}_{2}$ coating. Materials Letters. 2012;85:57-60.

9. Huang J, Song G, Lv H, Li Y, Sun Y, He X, et al. Microstructure and thermal cycling behavior of $\mathrm{CeO}_{2}$ coatings deposited by the electron beam physical vapor technique. Thin Solid Films. 2013;544:270-5.

10. Holcombe Jr CE, Chapman LR. High emissivity coating. United States Patents, 5668072; 1997.

11. Tan W, Adducci M, Petorak C, Thompson B, Brenner AE, Trice RW. Effect of rare-earth dopant $(\mathrm{Sm})$ concentration on total hemispherical emissivity and ablation resistance of $\mathrm{ZrB}_{2} / \mathrm{SiC}$ coatings. Journal of the European Ceramic Society. 2016;36(16):3833-41.

12. Vippola M, Keränen J, Zou X, Hovmöller S, Lepistö T, Mäntylä T. Structural characterization of aluminum phosphate binder. Journal of the American Ceramic Society. 2000;83(7):1834-6.

13. Formanek B, Szymański K, Szczucka-Lasota B, Włodarczyk A. New generation of protective coatings intended for the power industry. Journal of Materials Processing Technology. 2005;164:850-5. 14. De Sousa Meneses D, Melin P, del Campo L, Cosson L, Echegut P. Apparatus for measuring the emittance of materials from far infrared to visible wavelengths in extreme conditions of temperature. Infrared Physics \& Technology. 2015;69:96-101.

15. Juthapakdeeprasert J, Lerdprom W, De Sousa Meneses D, Jayaseelan DD, Lee WE, editors. CeO and $\mathrm{CePO}_{4}$ - containing high emissvity coating for basic refractory bricks. 61th International Colloquium on Refractories; 2018; Aachen, Germany.

16. Tsuhako M, Ikeuchi S, Matsuo T, Motooka I, Kobayashi M. Conditions of the formation of rare earth phosphates and the colors of their powders. Bulletin of the Chemical Society of Japan. 1979;52(4):1034-40.

17. Li Y, Chen L, Hong L, Ran K, Zhan Y, Chen Q. Fabrication of porous silicon carbide ceramics at low temperature using aluminum dihydrogen phosphate as binder. Journal of Alloys and Compounds. 2019;785:838-45.

18. Maslakov KI, Teterin YA, Ryzhkov MV, Popel AJ, Teterin AY, Ivanov KE, et al. The electronic structure and the nature of the chemical bond in $\mathrm{CeO}_{2}$ Physical Chemistry Chemical Physics. 2018;20(23):16167-75.

This article is protected by copyright. All rights reserved 
19. Adelstein N, Mun BS, Ray HL, Ross Jr PN, Neaton JB, De Jonghe LC. Structure and electronic properties of cerium orthophosphate: Theory and experiment. Physical Review B. 2011;83(20):205104.

20. Brun J, Del Campo L, De Sousa Meneses D, Echegut P. Infrared optical properties of $\alpha$-alumina with the approach to melting: $\gamma$-like tetrahedral structure and small polaron conduction. Journal of Applied Physics. 2013;114(22):223501.

21. Rousseau B, Brun J, Meneses DDS, Echegut P. Temperature measurement: Christiansen wavelength and blackbody reference. International Journal of Thermophysics. 2005;26(4):1277-86.

This article is protected by copyright. All rights reserved 


\section{Captions}

Figure 1. Viscosity of $\mathrm{CeO}_{2}$ mixed with $\mathrm{AlH}_{6} \mathrm{O}_{12} \mathrm{P}_{3}$ at different volume ratios.

Figure 2. Schematic of spraying process.

Figure 3. XRD of coatings heat treated at $1300^{\circ} \mathrm{C}, 3 \mathrm{~h}$. a) is of all three coatings for $15-65^{\circ} 2$ theta, b) is a magnified image of a) for $15-25^{\circ}$ 2theta. The coating contained different ratios of the composition of $\mathrm{CeO}_{2}$ : $\mathrm{AlH}_{6} \mathrm{O}_{12} \mathrm{P}_{3}$ of $1: 3,1: 5$ and $1: 12$ presented in green, red and blue, respectively. Circles $(\bullet)$ are $\mathrm{CeO}_{2}$ and diamonds $(\mathbf{\square})$ are $\mathrm{CePO}_{4}$.

Figure 4. SEM image of CBR 1:5 vol. $\mathrm{CeO}_{2}: \mathrm{AlH}_{6} \mathrm{O}_{12} \mathrm{P}_{3}$ cross section heat treated for $3 \mathrm{~h}$ at $1300^{\circ} \mathrm{C}$. a) overview image of the substrate and the coating. b) magnified image from boxed section shown in a) revealing pores, large grains $(\sim 10 \mu \mathrm{m})$, small grains $(\sim 2 \mu \mathrm{m})$ and a likely melt-formed phase. $c)$ magnified image from boxed section shown in b) revealing large $\left(\mathrm{CeO}_{2}\right)$ and small grains $\left(\mathrm{CePO}_{4}\right)$.

Figure 5. SEM and EDX image of CBR 1:5 vol. $\mathrm{CeO}_{2}: \mathrm{AlH}_{6} \mathrm{O}_{12} \mathrm{P}_{3}$ cross section heat treated for $3 \mathrm{~h}$ at $1300^{\circ} \mathrm{C}$

Figure 6. Schematic of cross section 1:5 ratio of $\mathrm{CeO}_{2}: \mathrm{AlH}_{6} \mathrm{O}_{12} \mathrm{P}_{3}$ coating on substrate developing as temperature increase. a) At room temperature, $\mathrm{CeO}_{2}$ particles settle in the $\mathrm{AlH}_{6} \mathrm{O}_{12} \mathrm{P}_{3}$ binder. b) At $900^{\circ} \mathrm{C}$, dehydrogenation of $\mathrm{AlH}_{6} \mathrm{O}_{12} \mathrm{P}_{3}$ occurs generating pores and $\mathrm{CePO}_{4}$ starts forming. c) At $1300^{\circ} \mathrm{C}, \mathrm{CePO}_{4}$ continues forming and the remaining $\mathrm{CeO}_{2}$ sinters.

Figure 7. STEM-EDX microstructure of the coating 1-5 a) STEM bright field image of particles (P) and matrix (M) area. b) EDX map of magnified (box) section shown in a). c) TEM diffraction pattern of $\mathrm{CePO}_{4}$ particles. d) Electron diffraction pattern of matrix indicating its glassy nature.

This article is protected by copyright. All rights reserved 
Figure 8. (a) Emissivity of $B R$ and $C B R$ at $1100^{\circ} \mathrm{C}$ and $1300^{\circ} \mathrm{C}$. The $x$-axis presents wavenumber $\left(\mathrm{cm}^{-1}\right)$ ranging from $700-12000 \mathrm{~cm}^{-1}$ and the $y$-axis of the graph presents emissivity ranging $0-1$. The red dash line, red solid line, black dash line, and black solid line represents BR emissivity at $1100^{\circ} \mathrm{C}, \mathrm{BR}$ emissivity at $1300^{\circ} \mathrm{C}, \mathrm{CBR}$ emissivity at $1100^{\circ} \mathrm{C}$ and $\mathrm{CBR}$ emissivity at $1300^{\circ} \mathrm{C}$ respectively. (b) magnified image from section shown in a) revealing Christiansen point, stretching of $\mathrm{PO}_{4}$ bond and effect from the $\mathrm{CO}_{2}$ laser.

Table 1. Power and temperatures achieve for BR and CBR

This article is protected by copyright. All rights reserved 
Table 1 Power and temperatures achieve for BR and CBR

\begin{tabular}{|c|c|c|}
\hline Power (Watts) & BR temperature $\left({ }^{\circ} \mathrm{C}\right)$ & CBR temperature $\left({ }^{\circ} \mathrm{C}\right)$ \\
\hline 18 & $505 \pm 20$ & $540 \pm 20$ \\
\hline 36 & $921 \pm 20$ & $1077 \pm 20$ \\
\hline 54 & $1125 \pm 20$ & $1194 \pm 20$ \\
\hline 71 & $1319 \pm 20$ & $1328 \pm 20$ \\
\hline 100 & $1550 \pm 20$ & \\
\hline
\end{tabular}

This article is protected by copyright. All rights reserved 


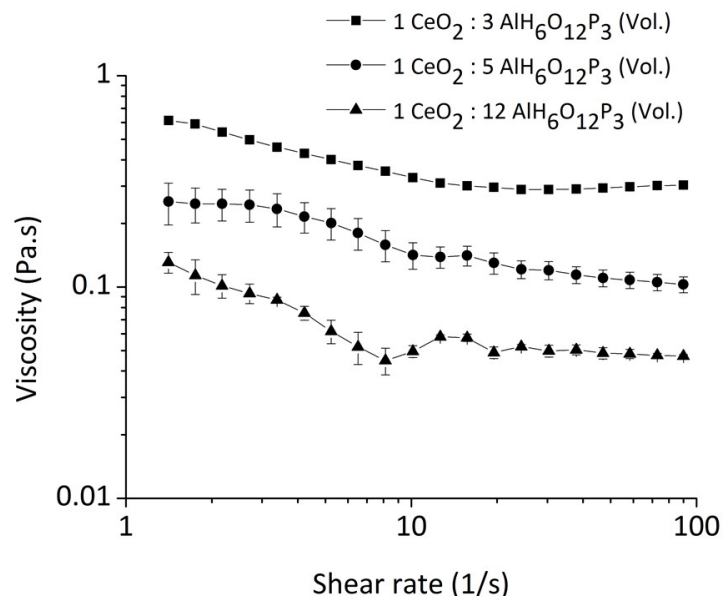

ijac_13416_f1.jpg 


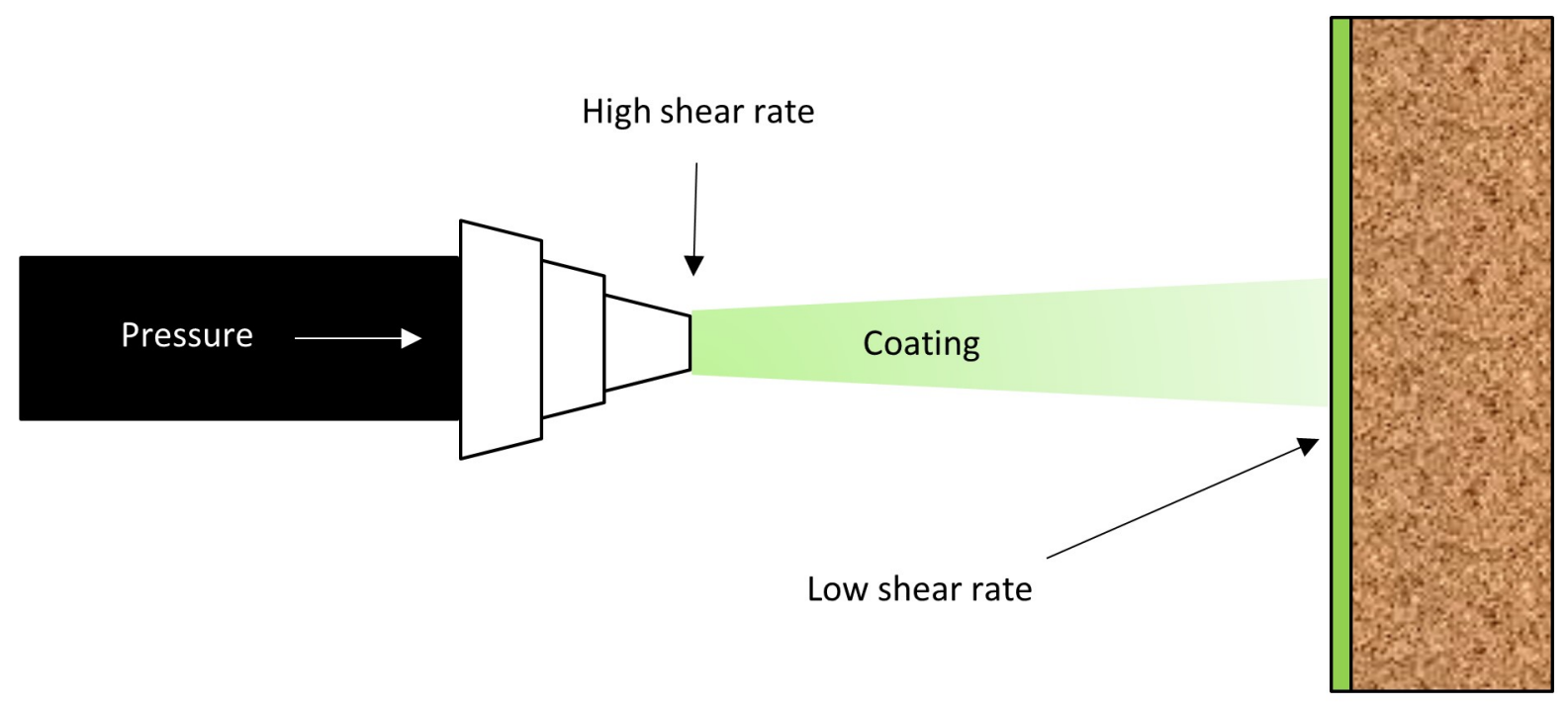

ijac_13416_f2.jpg 


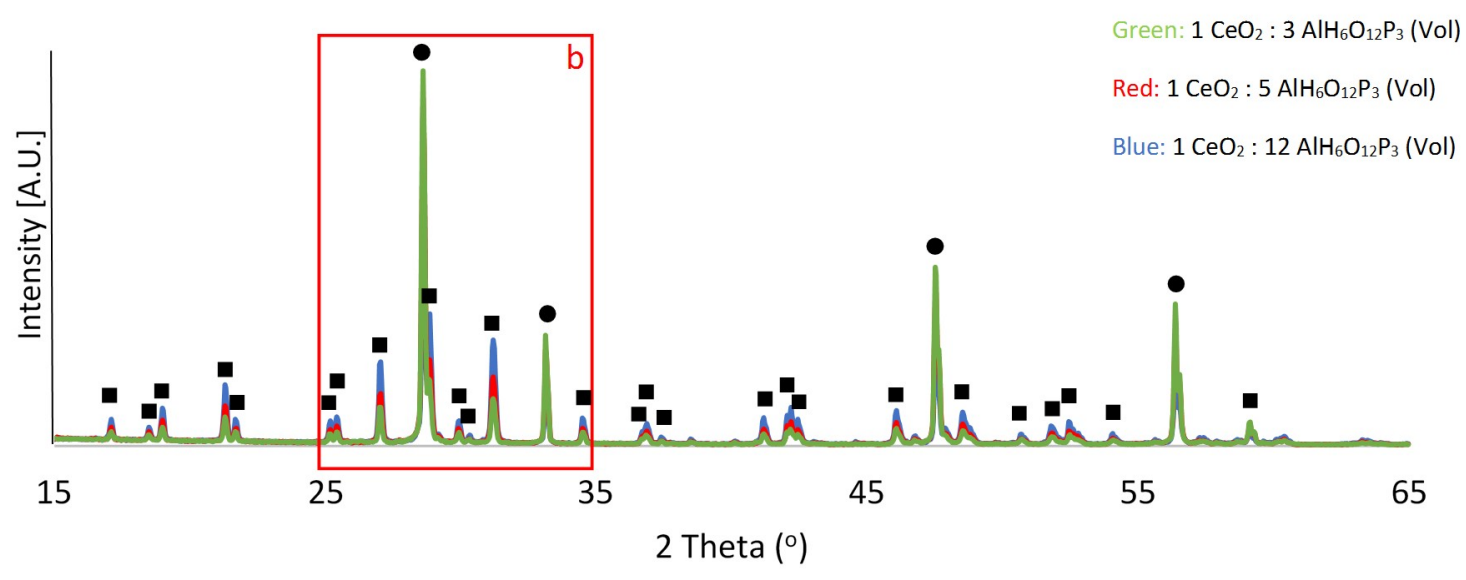

(a)

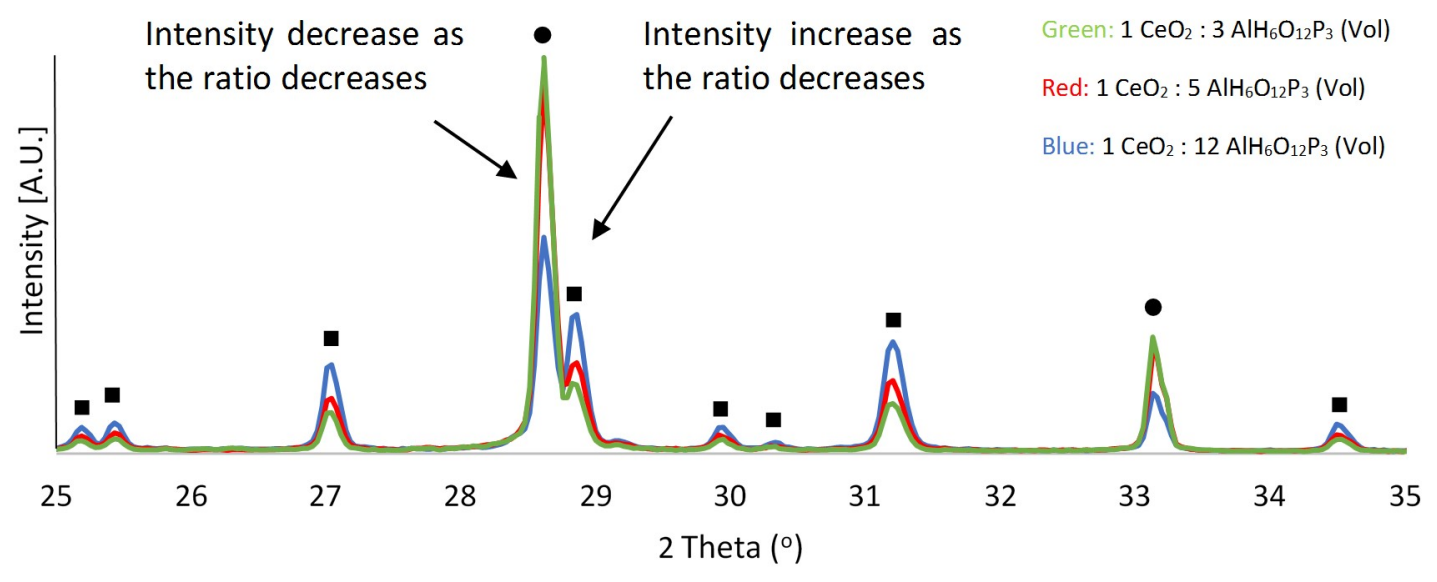

(b)

ijac_13416_f3.jpg 

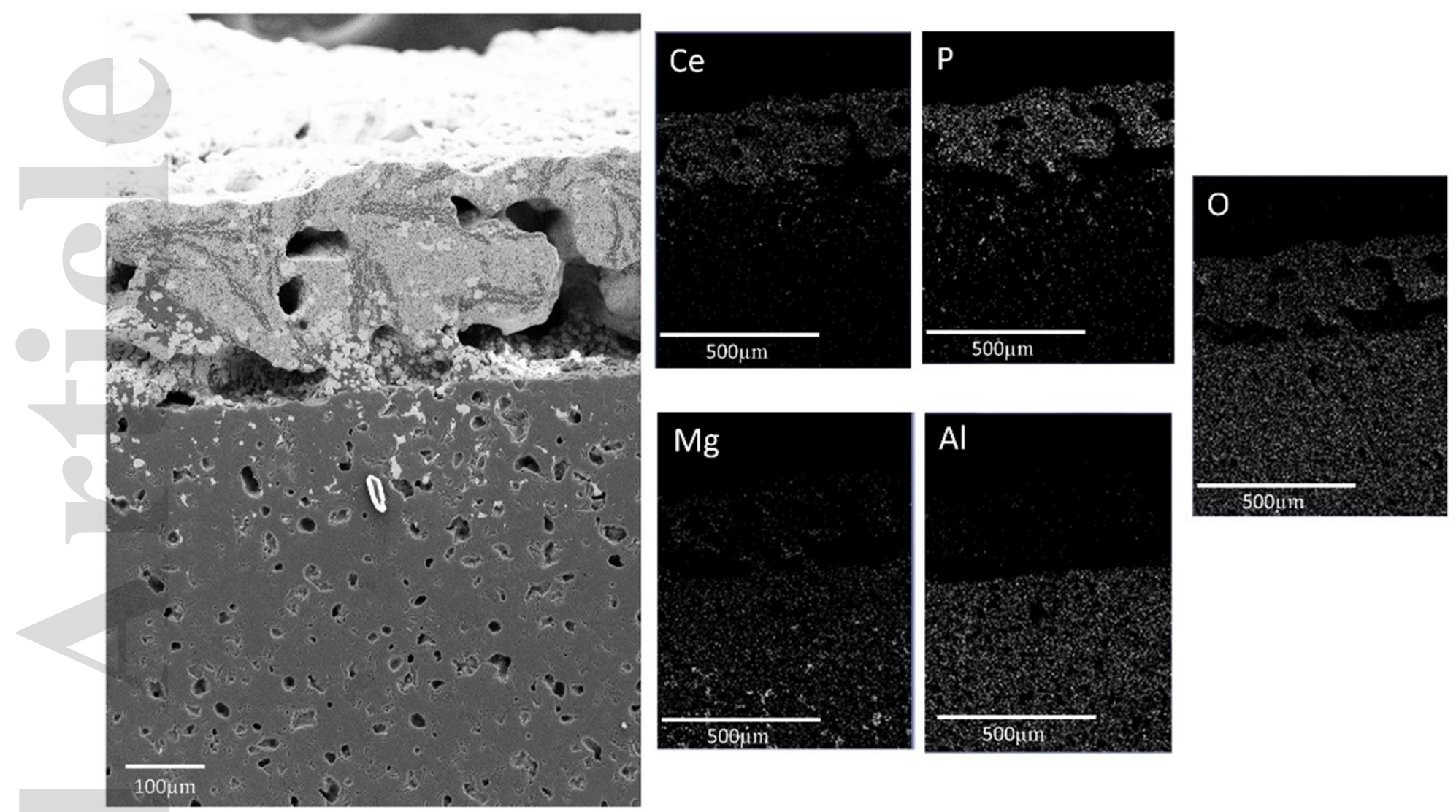

ijac_13416_f5.jpg 


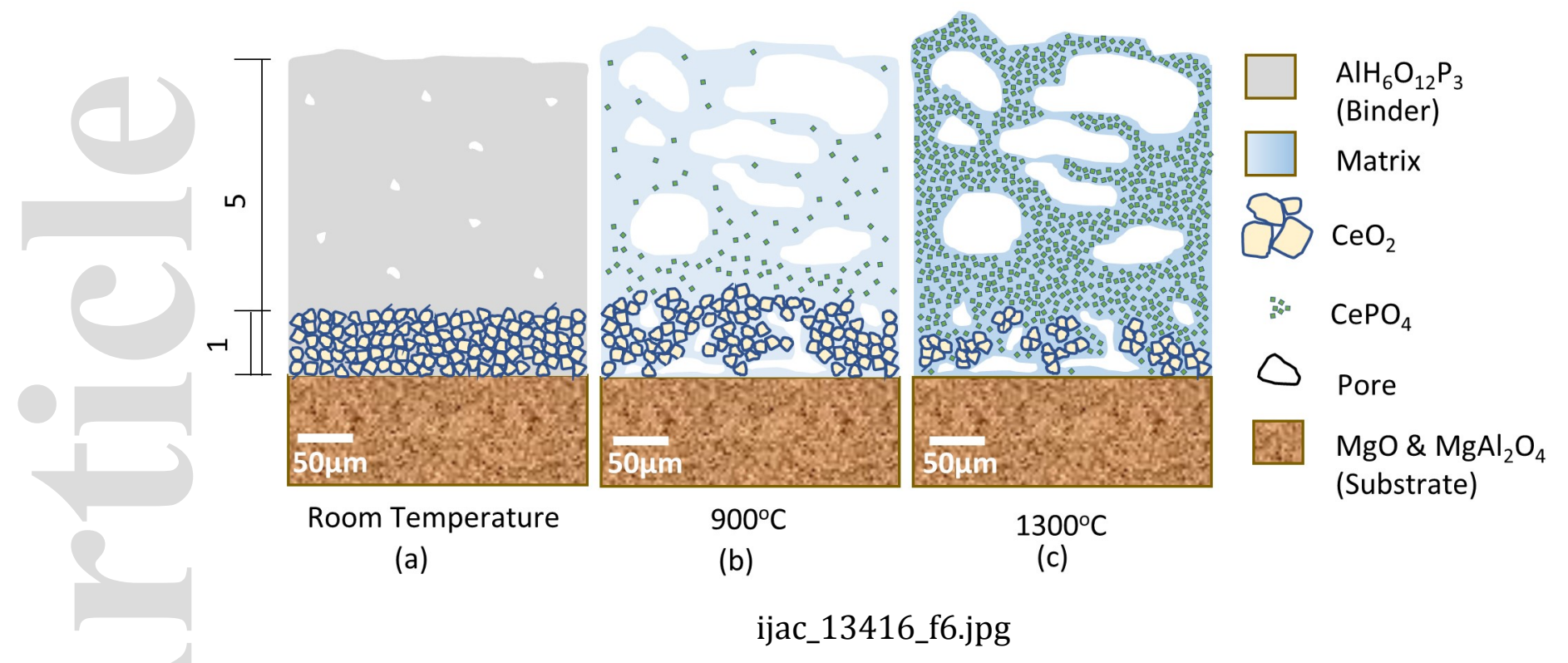

This article is protected by copyright. All rights reserved 


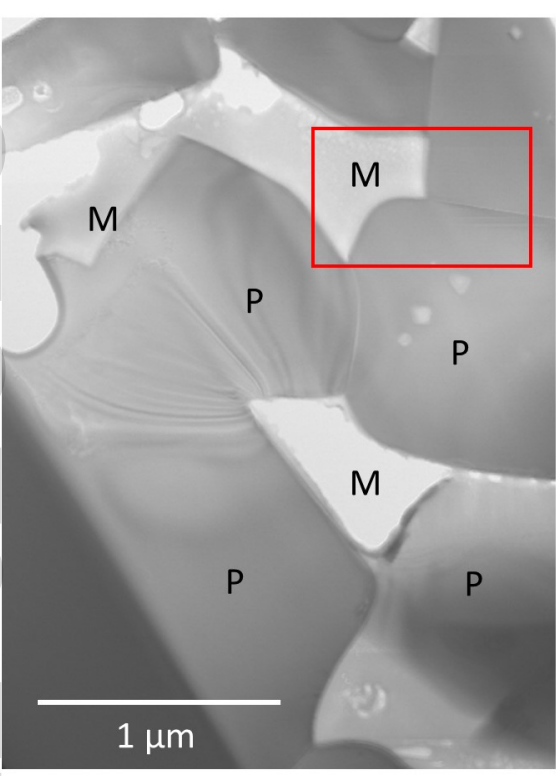

(a)
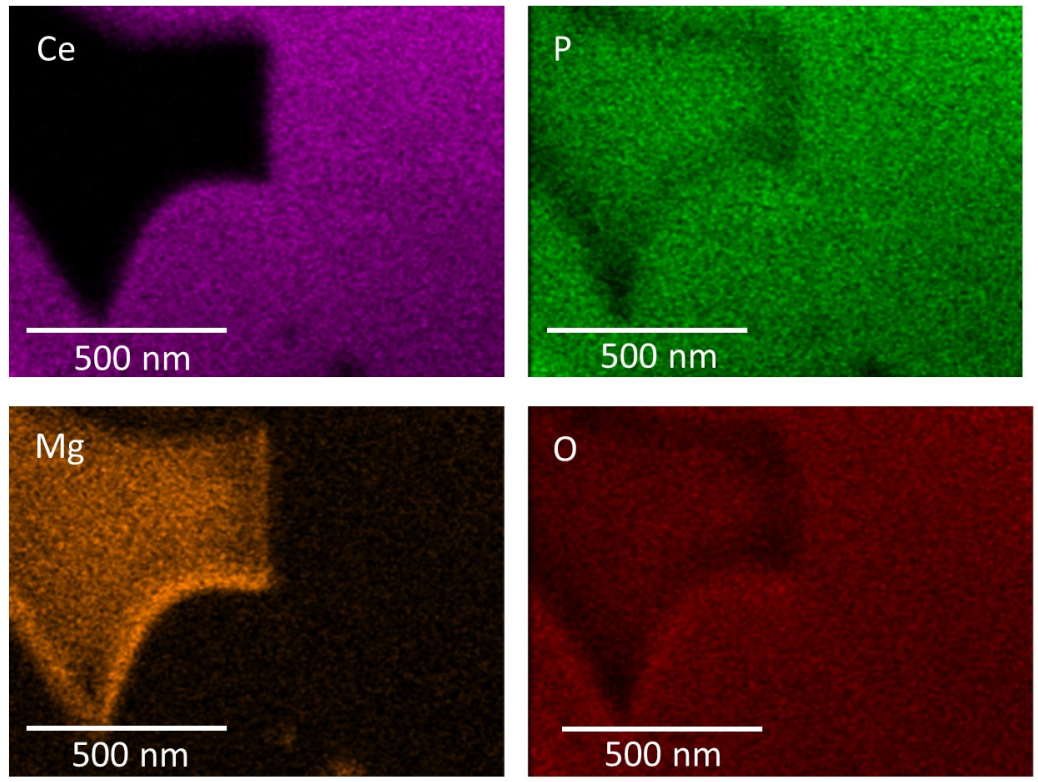

(b)

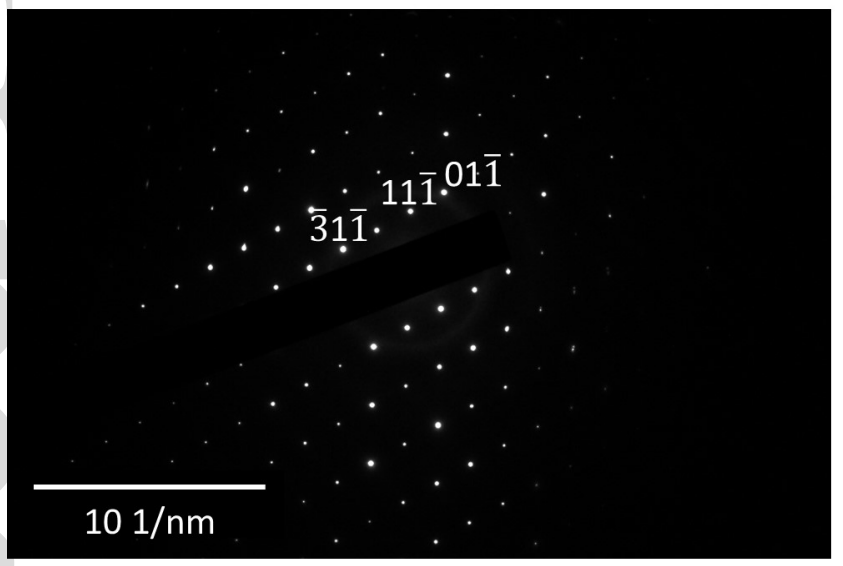

(c)

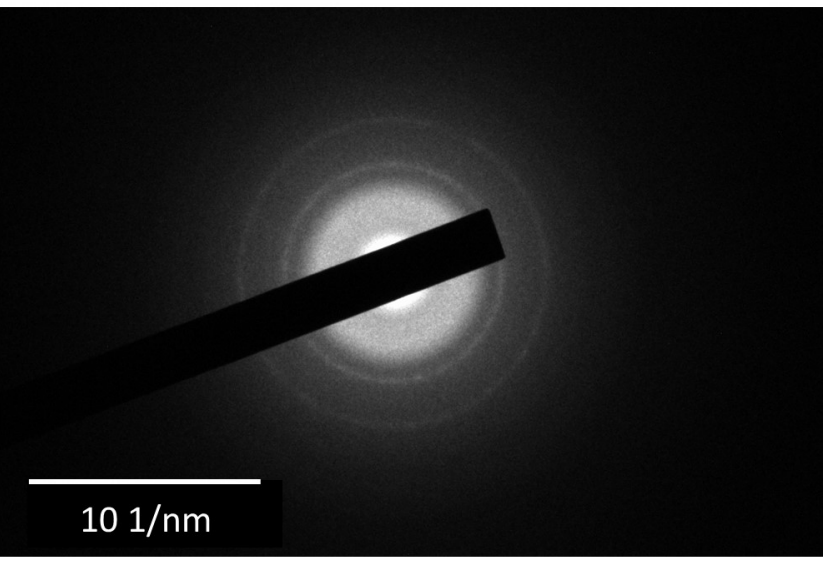

(d)

ijac_13416_f7.jpg 


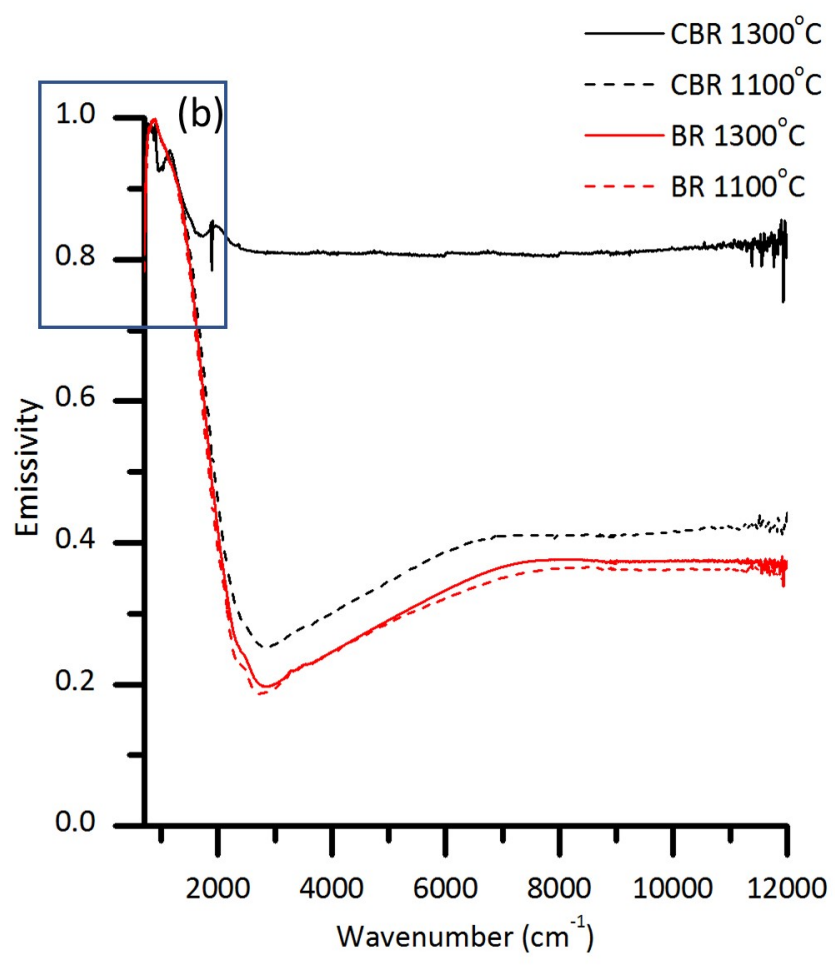

(a)

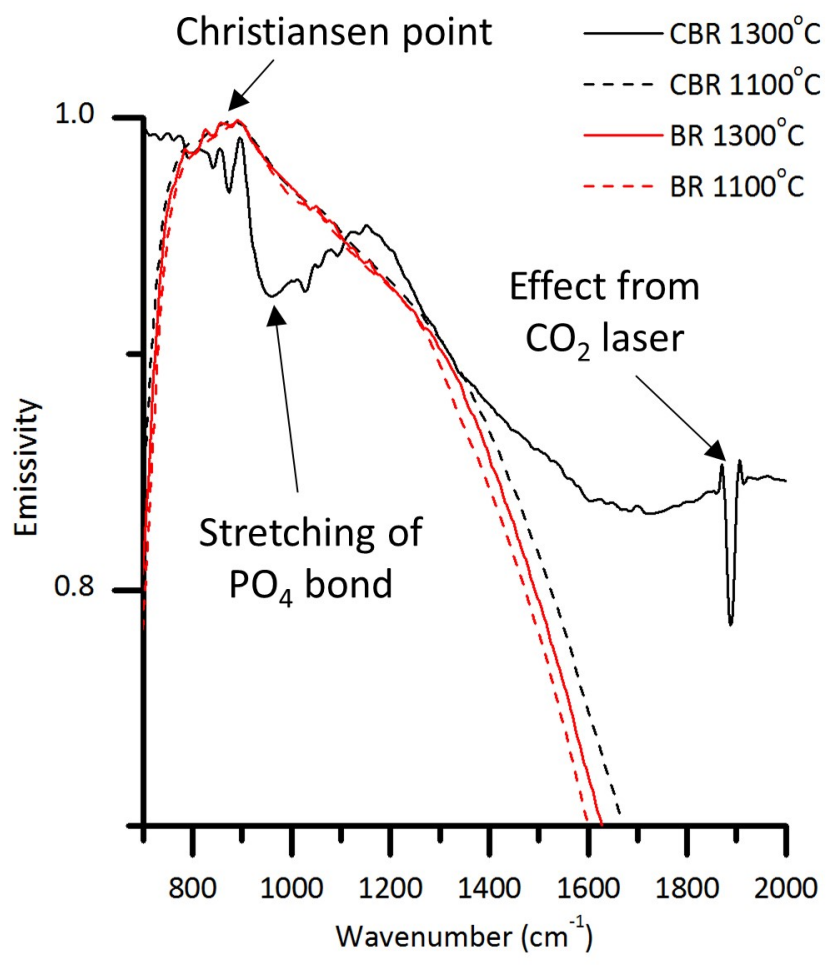

(b)

ijac_13416_f8.jpg

This article is protected by copyright. All rights reserved 